\title{
Non Small-Cell Lung Cancer Metastatic to the Mitral Valve: Case Report and Review of the Literature
}

\author{
Daniel J. Axelson, Natalie P. Kreitzer, Gregory J. Fermann \\ Department of Emergency Medicine, University of Cincinnati, Cincinnati, USA \\ Email: kreitzne@ucmail.uc.edu
}

Received 15 May 2014; revised 14 June 2014; accepted 13 July 2014

Copyright (C) 2014 by authors and Scientific Research Publishing Inc.

This work is licensed under the Creative Commons Attribution International License (CC BY). http://creativecommons.org/licenses/by/4.0/

(c) (i) Open Access

\begin{abstract}
In 2008, 1.6 million new cases of lung cancer were diagnosed worldwide, representing $13 \%$ of all cancer cases for the year, and in $2010,19 \%$ of cancer deaths were attributed to lung cancer. Though lung cancer frequently metastasizes to the adrenal glands, bone, brain, liver, and other lung, it infrequently metastasizes to the heart. Here, we report a case of lung cancer metastatic to the mitral valve.
\end{abstract}

Keywords

Lung Cancer, Myocardial Infarction

\section{Introduction}

MK was a 34-year-old African male who presented to the emergency department with the chief complaint of abdominal pain. He rated his pain at 8/10 in the center of his abdomen, with radiation into the right lower quadrant. His last normal bowel movement was several days ago. He had non-bloody, non-bilious emesis which he attributed to concurrent treatment for Stage 4 non-small cell lung cancer. He denied having a fever, diarrhea, shortness of breath, coughing, chest pain, or sore throat. He had a recent presentation and subsequent hospital admission for the same complaint two weeks prior to presentation. At that time, a CT scan of the abdomen and pelvis with IV and PO contrast had been negative. He had no prior history of abdominal surgeries. He had no known drug allergies. His medications were analgesics, anti-emetics, and the chemotherapeutic agent Erlotinib. He had emigrated from Senegal to the US several years ago.

On examination, the patient was ill appearing and cachectic. He was tachycardic with a heart rate in the $120 \mathrm{~s}$ to $130 \mathrm{~s}$. Vital signs were otherwise unremarkable. His abdominal exam revealed tenderness to palpation, re- 
bound and involuntary guarding in the mid epigastric region, right upper quadrant, and right lower quadrant. A bedside ultrasound of his right upper quadrant, performed by the emergency physician, demonstrated a normal appearing gallbladder, no pericholecystic fluid, no gallbladder wall thickening, and a normal common bile duct.

Pertinent labs revealed a WBC of 27,000 with $4 \%$ bands, a lactate of $2.0 \mathrm{mmol} / \mathrm{L}$. Abdominal plain films demonstrated a normal bowel gas pattern. A CT scan of the abdomen and pelvis with IV and PO contrast demonstrated a subtle peripheral hypo-density within the spleen and several new wedge shaped areas of low attenuation within both kidneys. These were concerning for infarcts of an embolic source, and were not present on the CT scan two weeks prior.

Blood cultures were obtained and the patient was administered IV Vancomycin and Gentamycin for presumed endocarditis. An EKG (electrocardiogram) performed as part of his workup for endocarditis demonstrated ST elevations in V3, V4, V5, and V6 (Figure 1). The Cardiology team was consulted regarding further diagnostic and therapeutic options. A bedside echo in the emergency department demonstrated distal anterior and apical hypokinesis, no pericardial fluid, and no gross valvular abnormalities. Cardiac Troponin I was elevated at 23.62 $\mathrm{ng} / \mathrm{dl}$. Given the clinical scenario, the cardiology team elected to proceed with left heart catheterization.

\section{Inpatient Course}

The patient was taken to the cath lab, where he was found to have a 100\% mid LAD occlusion. Debris was suctioned from his coronary vessels. After thrombus and debris aspiration, TIMI 2-3 flow was established and no stents were deployed. During the procedure a second coronary embolic event was visualized into one of the diagonal arteries. The aspirated thrombotic material was sent to the lab, and ultimately found to be consistent with clot. A gram stain of the material was negative for bacteria or fungus. Concurrent medical therapy post procedure did not initially involve anticoagulation. The patient was felt to have a high risk of bleeding with septic emboli, hemoptysis, and a small pericardial effusion. The effusion was not hemodynamically compromising, but was likely hemorrhagic. The oncology team, however, had concerns that the patient's presentation was consis-

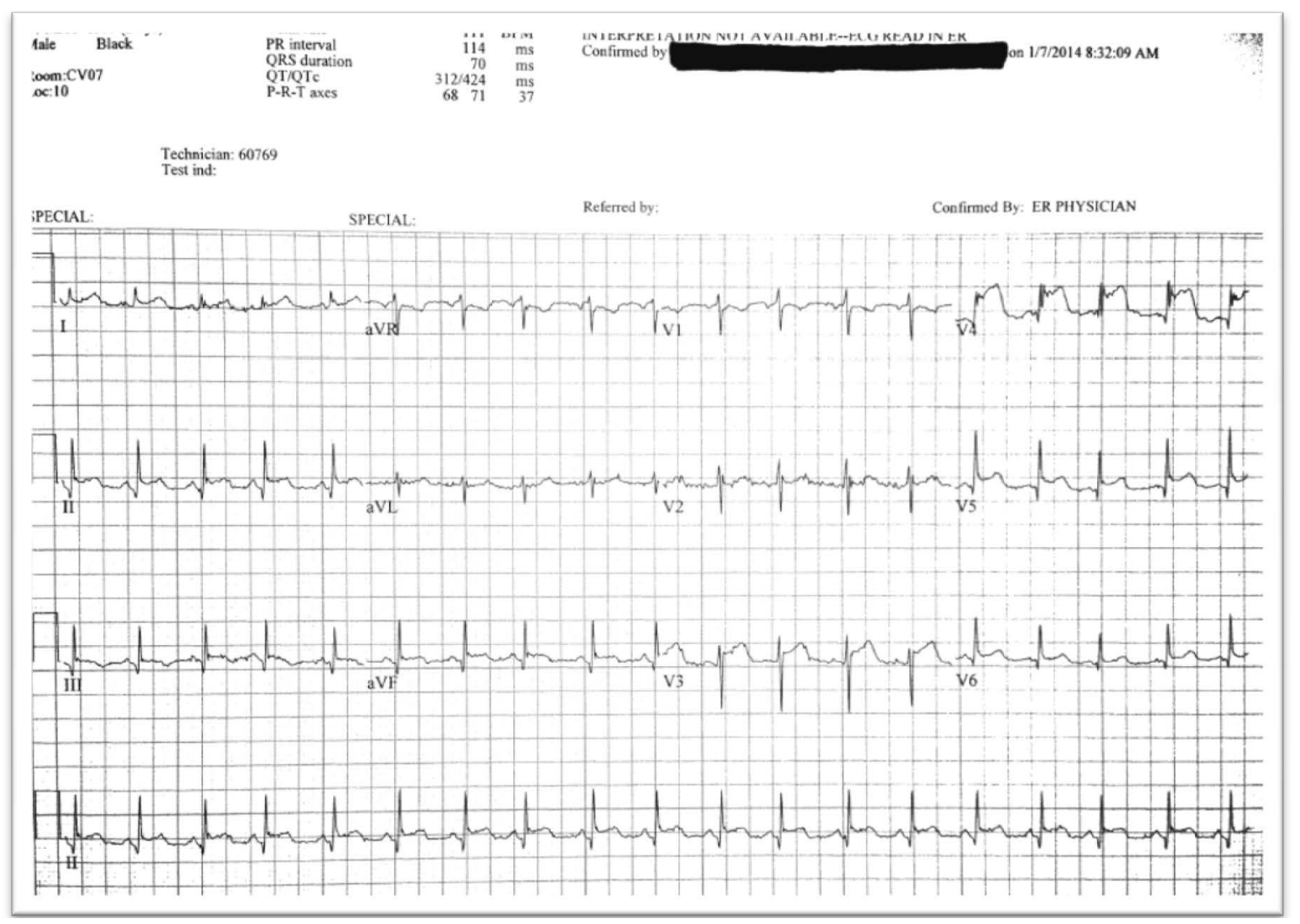

Figure 1. Electrocardiogram demonstrating diffuse ST elevations. 
tent with low grade DIC (thrombotic type), and he was started on a full dose unfractionated heparin infusion following a negative non-contrast head CT.

A repeat 2D echocardiogram demonstrated a globular mass associated with the lateral aspect of the anterior and posterior mitral leaflets (A1, P1), which likely represented a metastatic mass (Figure 2). There was mild mitral regurgitation as well. The left ventricle had severely reduced systolic function, with an ejection fraction of 30\% - 35\%, diffuse hypo-kinesis, and Grade 1 diastolic dysfunction. There was a small pericardial effusion present as well. The clinical picture suggested tumor embolization to the coronary arteries, spleen and kidneys. This was deduced based on the patient's blood cultures remaining negative throughout his hospital course. Although the patient initially wanted to continue treatment for his malignancy, therapeutic options were limited given the extent of his disease. Hospice care was arranged and the patient passed away shortly.

\section{Literature Review}

In 2008, 1.6 million new cases of lung cancer were diagnosed worldwide, representing $13 \%$ of all cancer cases for the year [1]. In 2010, lung cancer associated deaths rose to account for 19\% of all cancer deaths [2]. The vast majority of lung cancers ( 80\%) is non-small cell lung cancers (NSCLC) [3], and NSCLC patients present with locally advanced or metastatic disease more than $65 \%$ of the time [4]. The late manifestations of cardiac disease secondary to cancer treatments have been more rigorously documented [5]. However, much of what is seen of the different presentations related to NSCLC metastases comes from case reports in the literature. Case reports have documented the more acute, ischemic complications of metastatic NSCLC. Sadat et al. report a case of peripheral limb ischemia from primary lung neoplasm that had migrated to the heart [6]. The phenomenon of cardiac metastasis in NSCLC is very rare but has been documented in the literature even as a primary presentation of lung neoplasm [7]. In all cancer patients, somewhere between $10 \%$ and $15 \%$ of patients have been found
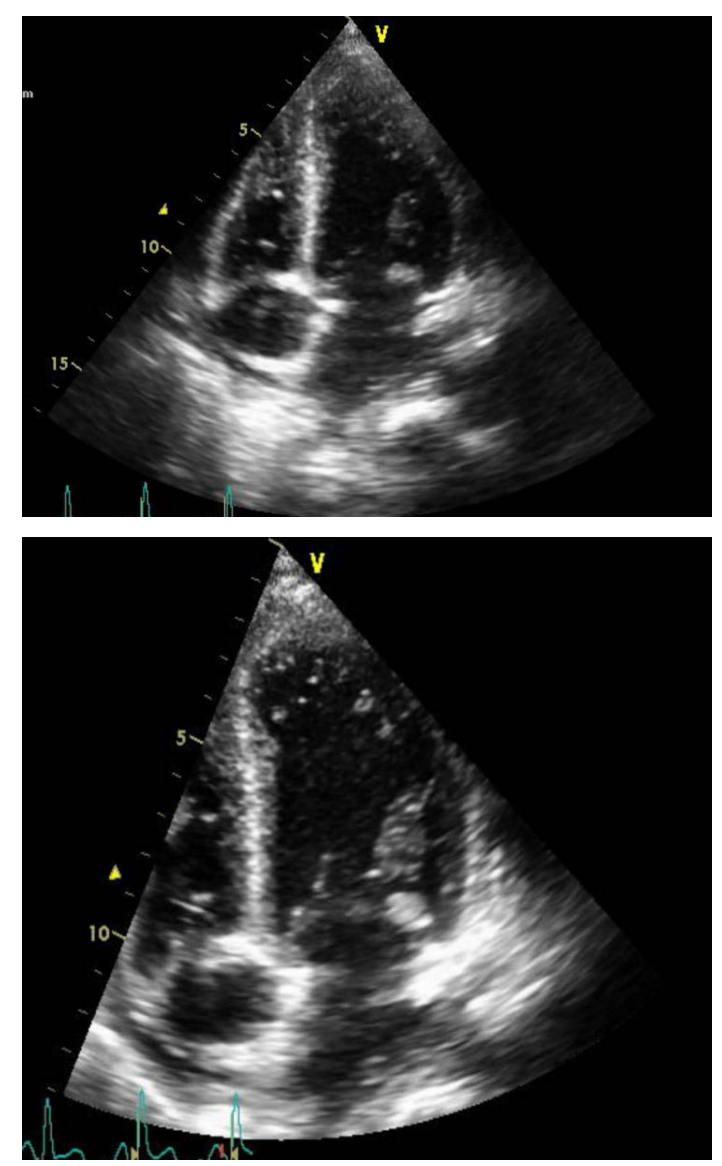

Figures 2. Globular mass associated with the lateral aspect of the anterior and posterior mitral leaflets. 
to have cardiac metastases on pathologic examination [8]. This number holds true with NSCLC, which has been estimated to invade the cardiac atria in up to $10 \%$ of cases [9]. To our knowledge, however, the specific incidence of mitral valve involvement with NSCLC is unknown. Cardiac metastases are found in advanced cancers and lead to significant morbidity. Liang et al. report a case of disseminated microvascular pulmonary tumor emboli leading to pulmonary hypertension and sudden cardiac death [10]. Leeies and Weldon report a case of occult malignancy first presenting as ST segment elevation myocardial infection (STEMI) with cardiac tamponade [11]. They appropriately call for the expanded use of ultrasound as a diagnostic modality in the evaluation of select cardiac patients in the ED.

Although cardiac metastases are rare, they are most commonly noted in lymphoma, leukemia, lung cancer, esophageal cancer, breast cancer, and melanoma [12]. In our patient's case, his atrial mass was thought to represent tumor that seeded from venous flow of the pulmonary vascular system into the heart. This was based on his echo images (shown below), persistently negative blood cultures, and pathology reports of extracted thrombus from the left anterior descending artery that was consistent with fibrin. Treatment of atrial invasion by NSCLC has been described in case reports to include radiotherapy and pneumonectomy with atrial resection [9] [13] [14]. However, cardiac involvement portends poor outcomes in NSCLC, with median survival after treatment with atrial resection reported at 25 months [13]. We have found no description of the treatment of nonsmall cell lung cancer metastatic to the mitralvalve in the literature.

Given the high likelihood of embolic complications from the valvular mass, surgery was presented as a treatment option for our patient. He elected to not pursue aggressive treatment for his condition, opting instead for home hospice care. This case represents an unusual presentation of cardiac involvement in NSCLC.

\section{References}

[1] Jemal, A., Bray, F., Center, M.M., Ferlay, J., Ward, E. and Forman, D. (2011) Global Cancer Statistics. CA: A Cancer Journal for Clinicians, 61, 69-90. http://dx.doi.org/10.3322/caac.20107

[2] Lozano, R., Naghavi, M. and Foreman, K., et al. (2012) Global and Regional Mortality from 235 Causes of Death for 20 Age Groups in 1990 and 2010: A Systematic Analysis for the Global Burden of Disease Study 2010. Lancet, 380, 2095-2128. http://www.ncbi.nlm.nih.gov/pubmed/?term=Lancet\%2C+380+(2012)++2095-2128 http://dx.doi.org/10.1016/S0140-6736(12)61728-0

[3] Devesa, S.S., Bray, F., Vizcaino, A.P. and Parkin, D.M. (2005) International Lung Cancer Trends by Histiologic Type: Male:Female Differences Diminishing and Adenocarcinoma Rates Rising. International Journal of Cancer, 117, 294299. http://www.ncbi.nlm.nih.gov/pubmed/?term=Int+J+Cancer\%2C+117+(2005)\%2C+294-299 http://dx.doi.org/10.1002/ijc.21183

[4] Morgensztern, D., Ng, S.H., Gao, F. and Govindan, R. (2010) Trends in Stage Distribution for Patients with Non-Small Cell Lung Cancer: A National Cancer Database Survey. Journal of Thoracic Oncology, 5, 29-33. http://www.ncbi.nlm.nih.gov/pubmed/?term=J+Thorac+Oncol\%2C+5+(2010)\%2C+29-33 http://dx.doi.org/10.1097/JTO.0b013e3181c5920c

[5] Lenihan, D.J. and Cardinale, D.M. (2012) Late Cardiac Effects of Cancer Treatment. Journal of Clinical Oncology, 30, 3657-3664. http://www.ncbi.nlm.nih.gov/pubmed/23008297 http://dx.doi.org/10.1200/JCO.2012.45.2938

[6] Sadat, U., Noor, N., See, T.C. and Varty, K. (2007) Peripheral Arterial Ischemia by a Primary Lung Tumour Invading Left Atrium. Lung Cancer, 57, 237-239. http://www.ncbi.nlm.nih.gov/pubmed/?term=Lung+Cancer.+2007+Aug\%3B57(2)\%3A237-9 http://dx.doi.org/10.1016/j.lungcan.2007.02.001

[7] Kim, J.H., Jung, J.Y., Park, Y.I., Hwang, S.I., Jung, C.S., Lee, S.H. and Yoo, C.W. (2005) Non-Small Cell Lung Cancer Initially Presenting with Intracardiac Metastasis. Korean Journal of Internal Medicine, 20, 86-89. http://www.ncbi.nlm.nih.gov/pubmed/?term=Korean+J+Intern+Med.+2005+Mar\%3B20(1)\%3A86-9 http://dx.doi.org/10.3904/kjim.2005.20.1.86

[8] Klatt, E.C. and Heitz, D.R. (1990) Cardiac Metastases. Cancer, 65, 1456-1459. http://www.ncbi.nlm.nih.gov/pubmed/?term=Cancer.+1990+Mar+15\%3B65(6)\%3A1456-9. http://dx.doi.org/10.1002/1097-0142(19900315)65:6<1456::AID-CNCR2820650634>3.0.CO;2-5

[9] Lee, P. and Kishan, A.U. (2012) Radiotherapy Is Effective for Primary Lung Cancer Invading the Left Atrium. BMJ Case Reports. http://www.ncbi.nlm.nih.gov.proxy.libraries.uc.edu/pubmed/22814990

[10] Liang, Y.H., Kuo, S.W., Lin, Y.L. and Chang, Y.L. (2011) Disseminated Microvascular Pulmonary Tumor Embolism from Non-Small Cell Lung Cancer Leading to Pulmonary Hypertension Followed by Sudden Cardiac Arrest. Lung 
Cancer, 72, 132-135. http://www.ncbi.nlm.nih.gov/pubmed/21333371 http://dx.doi.org/10.1016/j.lungcan.2010.12.022

[11] Leeies, M. and Weldon, E. (2011) STEMI Stymie: Metastatic Cancer and Cardiac Tamponade Presenting as Inferior STEMI. Annals of Emergency Medicine, 57, 221-224.

http://www.ncbi.nlm.nih.gov/pubmed/?term=Ann+Emerg+Med.+2011+Mar\%3B57(3)\%3A221-4 http://dx.doi.org/10.1016/j.annemergmed.2010.08.011

[12] Reynen, K., Kockeritz, U. and Strasser, R.H. (2004) Metastases to the Heart. Annals of Oncology, 15, 375-381. http://www.ncbi.nlm.nih.gov/pubmed/?term=Annals+of+Oncology+15\%3A+375-381\%2C+2004

[13] Ratto, G.B., Costa, R., Vassallo, G., Alloisio, A., Maineri, P. and Bruzzi, P. (2004) Twelve-Year Experience with Left Atrial Resection in the Treatment of Non-Small Cell Lung Cancer. Annals of Thoracic Surgery, 78, 234-237. http://dx.doi.org/10.1016/j.athoracsur.2004.01.023

[14] Spaggiari, L., D’Aiuto, M., Veronesi, G., Pelosi, G., de Pas, T., Catalano, G. and de Braud, F. (2005) Extended Pneumonectomy with Partial Resection of the Left Atrium, without Cardiopulmonary Bypass, for Lung Cancer. Annals of Thoracic Surgery, 79, 234-240. http://dx.doi.org/10.1016/j.athoracsur.2004.06.100 
Scientific Research Publishing (SCIRP) is one of the largest Open Access journal publishers. It is currently publishing more than 200 open access, online, peer-reviewed journals covering a wide range of academic disciplines. SCIRP serves the worldwide academic communities and contributes to the progress and application of science with its publication.

Other selected journals from SCIRP are listed as below. Submit your manuscript to us via either submit@scirp.org or Online Submission Portal.
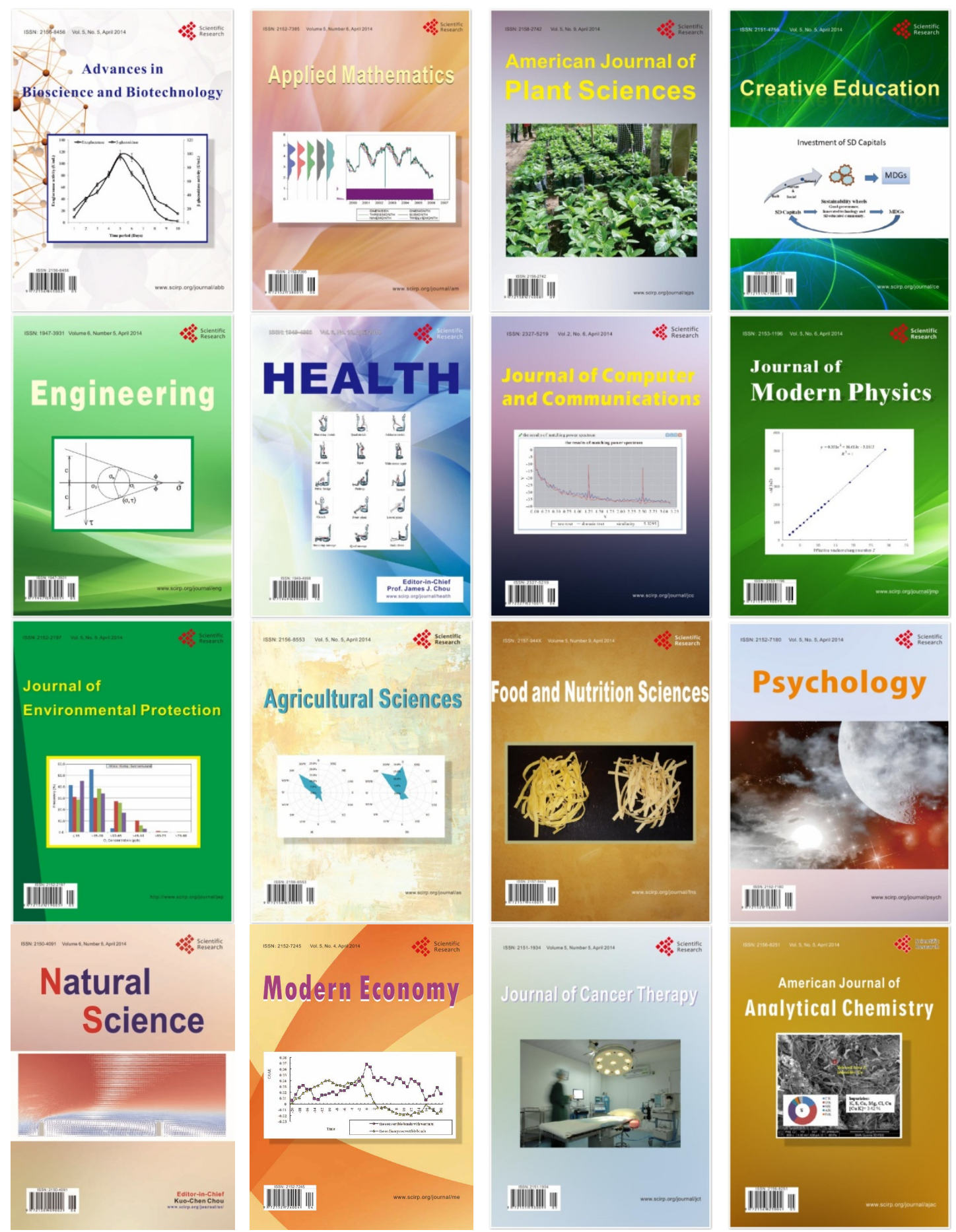